\title{
PRE-TREATMENT OF INDUSTRIAL WASTE WATER WITH HYDROCARBON SEPARATORS
}

\author{
Stefan Vasilica ${ }^{1}$, Simion Maria Andra ${ }^{2}$, Lucretia Popa ${ }^{1}$, Ancuta Nedelcu ${ }^{1}$, Radu Ciuperca ${ }^{1}$ \\ ${ }^{1}$ National Institute of Research-Development for Machines and Installations Designed to Agriculture \\ and Food Industry, Romania; ${ }^{2}$ PURECO Environment SRL, Romania \\ valle_vali@yahoo.com, andra.simion@pureco.ro, lucretia_popa@yahoo.com, nedelcuus@yahoo.com, \\ ciupercaradu@yahoo.com
}

\begin{abstract}
The aim of the article is to present a pre-treatment of industrial waste water with hydrocarbon separators. Three hydrocarbon separators with a coalescing filter were tested in three different situations (car wash, fuel station and parking lot). The quality of treated water that is leaving the separator must comply with the conditions of NTPA 001/2005 for wastewater discharge into natural receivers. The maximum amount of light liquid hydrocarbons in the effluent separator is $5 \mathrm{mg} \cdot \mathrm{l}^{-1}$. Petroleum products at concentrations of 0.1 to $10 \mathrm{mg} \cdot \mathrm{l}^{-1}$ present in the surface area and wastewater are determined spectrophotometrically according to SR 7877-2/1995, petroleum products together with some substances present in water are extracted at $\mathrm{pH}<5$ in $\mathrm{CCl} 4$ (Carbon tetrachloride). Pre-treatment of polluted water discharged into the environment or into the sewage system is a necessity in order to protect the environment. Sizing the three light liquid separators is based on the nature and flow rate of the liquids to be treated and considering the following: the maximum flow of rainwater, the maximum flow of wastewater (e.g. industrial effluent), the density of the light liquid, presence of the substances that may impede separation (e.g. detergents). Oil separators nominal size is determined by the flow rate of $45 \mathrm{l} \cdot \mathrm{h} \cdot \mathrm{m}^{-2}$ for areas not covered. A coefficient of 0.5 is applied to the surfaces provided with the cover. The novelty of the proposed separation system is that in a steal tank all components are introduced: the hydrocarbon separator with a coalescing filter, retention tank and the pumping station. Thus, by integrating all components into a single container divided into several independent compartments, savings in space and mounting time are achieved.
\end{abstract}

Keywords: coalescing filter, hydrocarbon separator, waste water, pre-treatment, environmental protection.

\section{Introduction}

Contamination of the environment that surrounds us with certain materials that endanger human health, the quality of life or the natural functioning of ecosystems is called pollution. Pollution affects water, air and soil to the same extent. Air and water pollution is largely made by removing hydrocarbons from non-combustible fuels. The effects of hydrocarbon water pollution are: taste and unpleasant smell of water, prevention of surface oxygen absorption (self-cleaning), toxicity to aquatic flora and fauna, impossibility of using polluted water to supply irrigation facilities, recreation, etc.

For these reasons it is necessary to pre-treat the water discharged into the environment by:

- separating hydrocarbons from wastewater resulting from industrial processes, washing of vehicles, cleaning of lubricated oil components or other sources (fueling station yards, hydrocarbon storage area, etc.);

- pre-treating meteoric water contaminated by oils coming from waterproof areas (car parks, airports, industrial platforms, vehicle fleets, roads, factory yards, markets, etc.).

Hydrocarbon separators are based on the specific weight difference between water and hydrocarbons (gravitational separation) or solids in wastewater as follows: wastewater containing oil and hydrocarbon residues is collected from drainage platforms and channels and enters the separator by means of a calming and smoothing device [1-3].

As the wastewater flows slowly and evenly through the main body of the separator, coarse particles and suspended solids decant to the bottom (sludge hatch) forming a sludge layer, while the oil and hydrocarbons, lighter than water, rise to the surface. Due to the internal partition and the special construction of the outlet device, only the filtered water is evacuated, while the sludge, oil and hydrocarbons are kept inside. For these reasons hydrocarbon separators do not require external sources of energy or chemicals.

Gravitational separation is the most used method for separating water suspensions. The gravitational separation phenomenon is based on the difference between the water and suspension densities and occurs in two forms, namely: 
- sedimentation - which is a gravitational deposition phenomenon of suspensions with densities higher than water;

- flotation - the formation of a film on the surface is a phenomenon of rising the suspensions with a lower density than water to the surface, forming a separate suspension film.

The phenomenon of forming a separate film on the water surface may naturally occur for hydrophobic particles with a lower density than water (e.g., fats, oils, etc.) and is more intense as the difference in density of water and particles is higher. In practice, very small particles do not rise. For this reason, the flotation is artificially produced by means of coalescing filters. They are made of a spongy material that does not retain water; fine oil/hydrocarbon particles adhere to the surface of the coalescing filter. By combining several fine drops, a larger drop of oil is formed that can float naturally. In this way, the separation process inside a hydrocarbon separator does not require external energy sources, such as the introduction of air bubbles [1;4-6].

\section{Materials and methods}

The separation systems for light liquids and their components must comply with environmental regulations, withstand various loads (their own weight, payload, earth pressure, water pressure), ensure that the light liquids separated cannot be accidentally or uncontrolled discharged.

Coalescing filter separator. These separators are equipped with a filter that is positioned at the outlet and helps separate fine particles of oils/hydrocarbons from wastewater (Fig. 1). These fine particles reach the coalescing filter, where they combine with other fine particles, resulting in larger drops that are then released from the filter and separate by rising to the surface.

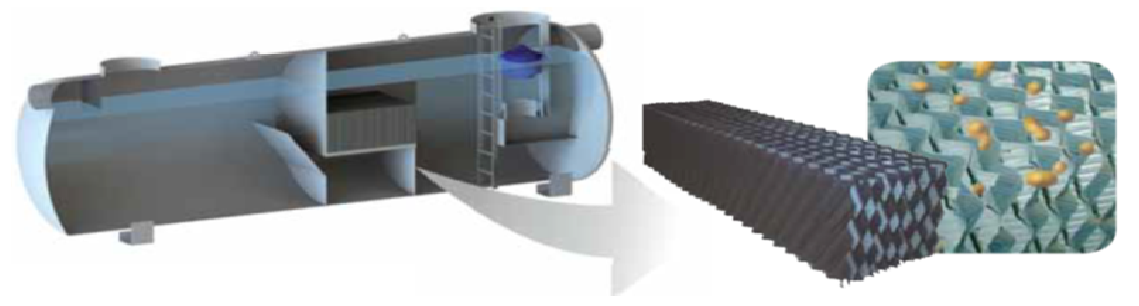

Fig. 1. Hydrocarbon separator with coalescing filter [7]

Bypass separator. It has the same operating principle as a normal separator (Fig. 2), but it allows treating large flows that can occur in the event of a storm. In case of abundant rainfall, it is considered that only the first water washed on the platforms is contaminated with hydrocarbons. This water enters the hydrocarbon separator to be treated and excess flows (considered to be only uncontaminated rainwater) pass through the bypass system without disrupting the separator (Fig. 3). The hydrocarbon separators are provided with an automatic closing system (calibrated for fluids with densities between 0.85 and $\left.0.95 \mathrm{~g} \cdot \mathrm{cm}^{-3}\right)[7 ; 8]$. Thus, when the accumulated hydrocarbon layer exceeds the capacity for which the separator was provided, the automatic closing device obstructs the outlet of the separator, not allowing the discharge of the hydrocarbons into the environment. The bypass separator generally treats $20 \%$ of the water flow rate, with the remaining $80 \%$ passing through the bypass without any treatment process.

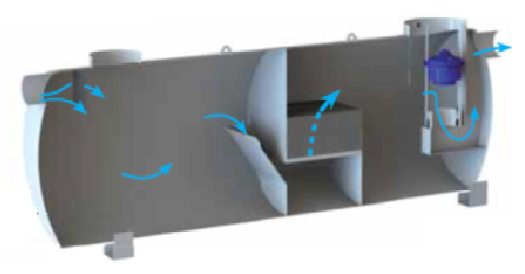

Fig. 2. Decanter, hydrocarbon separator with automatic shutter [7]

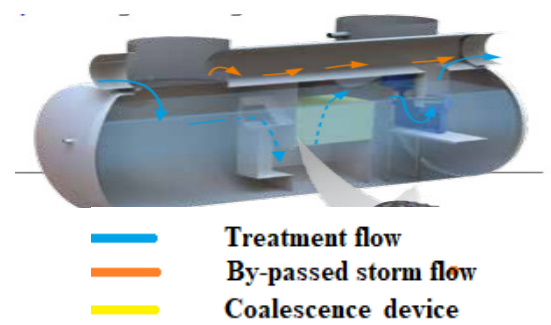

Fig. 3. Decanter, hydrocarbon separator with automatic shutter and bypass line [7]

The hydrocarbon separators are made in compact variants, the sludge hatch, the automatic shutter and the coalescing filter being in a single container made of reinforced concrete, steel or PE. This fact 
results in space saving, reducing the installation costs, if necessary. At the top, there are one or more inspection chambers that are used for sampling, drainage of sludge and hydrocarbons retained by it and for access to the installation, if necessary (repair, maintenance) [7].

Hydrocarbon separators made of reinforced concrete, for meteoric waters, are gravitational separation systems of sludge and oils, with high efficiency, which allow the elimination of suspended particles by gravitational decantation and the treatment and elimination of oils/hydrocarbons with a density $<0.85 \mathrm{~g} \cdot \mathrm{cm}^{-3}$ not emulsified from wastewater by static separation and coalescence filtration with efficiency $>95 \%$.

This treatment unit consists of one or more compartments:

- An inlet decanter compartment, dimensioned by the formula $100 \mathrm{x}$ TN of the device (TN corresponds to the treatment flow of the device - TN is defined in the literature as the nominal size). The volume of this compartment allows the capture of solids with diameters larger than 200 microns [4].

- A separator compartment dimensioned by the formula $90 \times \mathrm{TN}$ of the device. It is equipped with a decanting cell and an automatic shutter. Decanting cells improve the separation efficiency compared to a static type device. They allow obtaining a hydrocarbon level $\leq 5 \mathrm{mg} \cdot l^{-1}$ present to be evacuated under test conditions according to SR EN 858-1 [2-6]. This cell can be made of rigid and removable PVC modules to facilitate maintenance operations. Its high rigidity allows cleaning by high-pressure water jetting.

The coalescing filter aims to accelerate separation by acting through the coalescence of hydrocarbon microdrops. Thus, the effluent transits this filter sideways, while favoring hydrocarbon flotation. The hydrocarbon particles do not have enough density to rise to the surface and they stick to the sides of the filter and form a film that migrates upward, pushed by the ascending stream. The automatic closing system provides total protection against the risk of accidental discharge of hydrocarbons in the environment. The components of the closing system are made of polyethylene. The device closing system consists of a piece calibrated at a density of $\sim 0.85 \mathrm{~kg} \cdot \mathrm{dm}^{-3}$. Its movement is vertical, guided through a PVC tube. The internal bypass is made up of a PVC pipe, through which flows higher than the nominal flow (TN) are taken over [7].

Hydrocarbon separators in steel type tanks are an alternative solution to classical reinforced concrete and polyethylene separators. Corrugated steel tubes have been used for decades to build highways to create drainage channels, because although they have a thin wall their spiral structure ensures good load resistance. The advantage of using this type of separators is the low weight of the separator, about 5-6\% of the weight of the reinforced concrete ones, yet having its own load bearing capacity. The tubes are galvanically coated with $700 \mathrm{mg}$ zinc/m2 and the epoxide film on the outside and inside of the tube makes them some of the most resistant products. For example, spheroidal graphite cast iron pipes used to make water supply networks are coated with a layer of zinc (300 $\mathrm{mg} \cdot \mathrm{m}^{-2}$ ) and epoxy, and are compliant with all the requirements imposed by this use. Due to the applied epoxy layer, the hydrocarbon separator resists very well the corrosion phenomena [8].

The quality of the treated water at the outlet of the separator must comply with the conditions imposed by [3] for discharging wastewater into natural receivers and according to [2] for discharging water in the treatment plants. The maximum amount of light liquids in the effluent of the hydrocarbon separators is $5 \mathrm{mg} \cdot \mathrm{l}^{-1}[2 ; 3 ; 9 ; 10]$.

The nominal size of hydrocarbon separators shall be determined on $t$ he basis of a flow rate of 45 $1 / \mathrm{h} / \mathrm{m}^{2}$ for uncovered surfaces. A coefficient of 0.5 is applied for the surfaces provided with the cover. The size of the light liquid separators is based on the nature and flow of the treatment liquids and takes into account the following elements: maximum rainwater flow rate, maximum wastewater flow (e.g. industrial effluents), light liquid density, presence of liquids which can prevent separation (detergents, for example) [4;5].

The size of the separator for a car wash is determined by the formula: $[1 ; 5 ; 7]$.

$$
T N=\left(Q_{r}+\left(Q_{s} \times f_{x}\right)\right) \times f_{d},
$$

where $T N-$ nominal size of the separator, 
$Q_{r}$ - maximum flow rate of meteoric waters, $\left[1 \cdot \mathrm{s}^{-1}\right]$;

$Q_{s}$ - maximum wastewater flow rate, $\left[1 \cdot \mathrm{s}^{-1}\right]$;

$f_{x}$ - density of the respective light liquid (it will be 1 for a density less than 0.85 );

$f_{d}$-implementation factor depending on the nature of the discharge (it will be considered

2 according to EN 858-2).

The total wastewater flow rate corresponds to the sum of the flows according to the formula $[1 ; 7]$ :

$$
Q=Q_{s 1}+Q_{s 2}+Q_{s 3}+\ldots . .
$$

where $Q_{s 1}$ - flow rate from the supply taps,

$Q_{s 2}$ - flow rate from laundromats,

$Q_{s 3}$ - high pressure washing units,

$\ldots-$ all other flow rates.

For uncovered surfaces (e.g. car parks), the maximum decennial flow depends on the surface from which the water is to be treated and the local intensity of the rain in that area (three geographic areas 1 , 2 or 3 are noted according to Fig.4). For surfaces $>10000 \mathrm{~m}^{2}$, the calculation method according to NF EN 752-4 is the following [1;7]:

$$
Q_{10}=Q_{T}=\Psi \times I \times A,
$$

where $Q_{10}$ - maximum decennial flow rate, $1 \cdot \mathrm{s}^{-1}$;

$Q_{T}$ - treatment flow rate, $1 \cdot \mathrm{s}^{-1}$;

$\Psi$ - drainage coefficient (depending on surface nature: 0.9 for concrete or asphalt)

$I$ - Intensity of calculation rainfall $\left(1 \cdot \mathrm{s}^{-1} \cdot \mathrm{ha}^{-1}\right)$ according to the three geographic areas (decennial flow rate): UTC $1300 \mathrm{l} \cdot \mathrm{s}^{-1} \cdot \mathrm{ha}^{-1}$ - AREA 2: $400 \mathrm{l} \cdot \mathrm{s}^{-1} \cdot \mathrm{ha}^{-1}-$ AREA 3: $500 \mathrm{l} \cdot \mathrm{s}^{-1} \cdot \mathrm{ha}^{-1}$;

$A$ - uncovered area, ha.

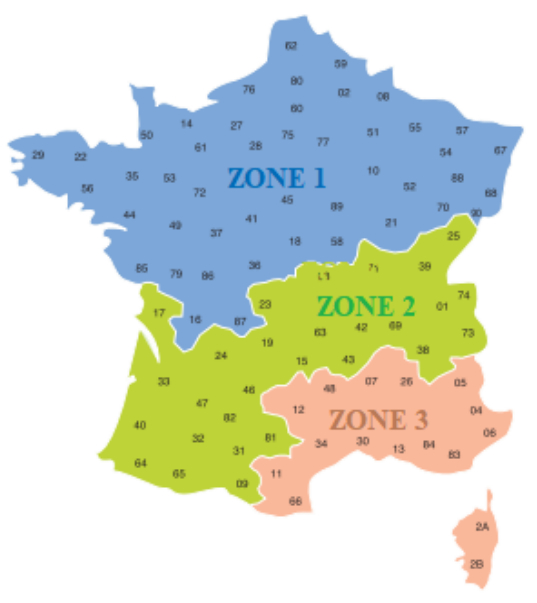

\begin{tabular}{|c|c|c|}
\hline ZONE 1 $\left(\mathrm{m}^{2}\right)$ & ZONE 2 $\left(\mathrm{m}^{2}\right)$ & ZONE $3\left(\mathrm{~m}^{2}\right)$ \\
\hline $1-90$ & $1-65$ & $1-55$ \\
\hline $91-145$ & $66-110$ & $56-85$ \\
\hline $146-255$ & $111-190$ & $86-155$ \\
\hline $256-330$ & $191-250$ & $156-200$ \\
\hline $331-405$ & $251-300$ & $201-265$ \\
\hline $406-630$ & $301-470$ & $266-375$ \\
\hline $631-810$ & $471-610$ & $376-485$ \\
\hline $811-1000$ & $611-750$ & $486-610$ \\
\hline $1001-1200$ & $751-900$ & $611-720$ \\
\hline $1201-1380$ & $901-1020$ & $721-830$ \\
\hline $1381-1570$ & $1021-1160$ & $831-940$ \\
\hline $1571-1700$ & $1161-1270$ & $941-1030$ \\
\hline $1701-1900$ & $1271-1450$ & $1031-1150$ \\
\hline
\end{tabular}

Fig. 4. Geographic areas (decennial flow) for designing no bypass separators [7]

According to the ISGH Quality Charter (the trade association ISGH, founded in 2003 which brings together manufacturers of prefabricated equipment for purification of rain water; it is affiliated with both the UIE and FNTP), sizing of a separator is done as follows (Fig. 5) for devices with a unique separation compartment, the total useful volume of the device will be at least [7]:

$$
V_{u}=90 \times D N \text {. }
$$

The sizing of a device made up of the decanter and separator according to the charter will have the useful volume [7]:

$$
V_{u}=190 \times D N
$$




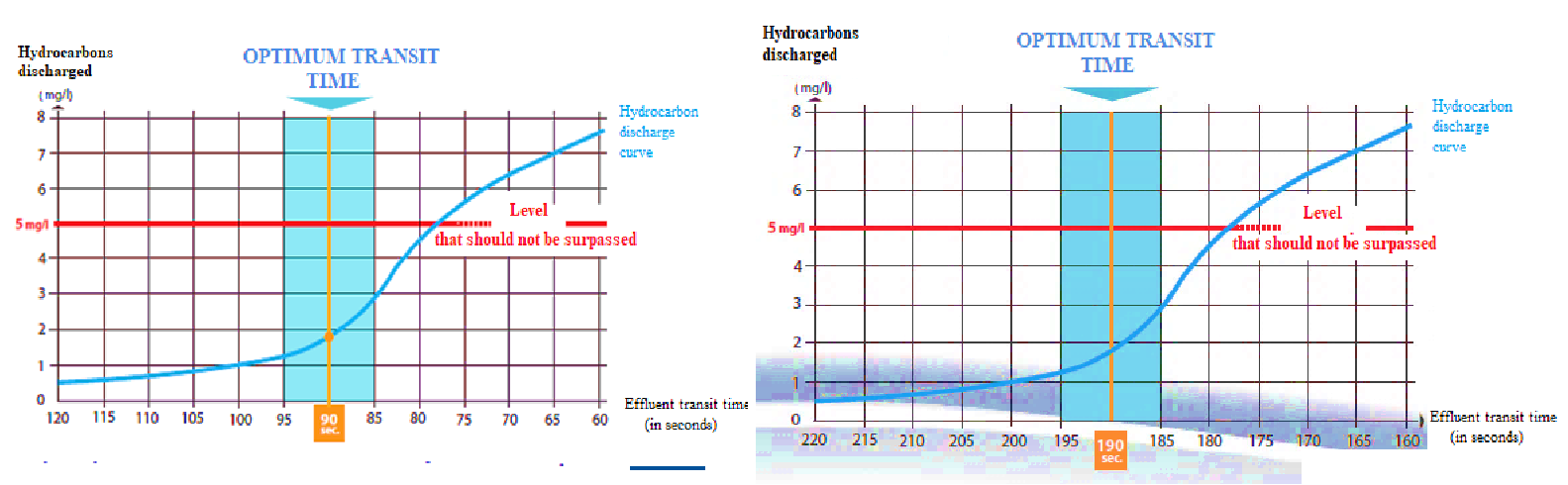

Fig. 5. Minimum total useful volume of storage of hydrocarbons [7]

The Charter estimates a "minimum useful volume" for optimal separation and storage of hydrocarbons. For example, at a nominal size of $100 \mathrm{l} \cdot \mathrm{s}^{-1}$, the minimum total useful volume of the device should be equal to [7]:

$$
V_{u}=190 \mathrm{~s} \times 1001 \cdot \mathrm{s}^{-1}=190001
$$

for a decanter equipped device.

Particles with a lower density than the fluid are separated by flotation in separators without forced aeration, as they float to the surface. In the case of natural flotation, the most important parameters are: the density difference between the two phases, particle rising speed, average temperature, dynamic viscosity of the multiphase mixture, adhesion coefficient and the flotation speed.

The particle rising speed is determined by Stokes law, which is valid for the Reynolds subunit number $[1 ; 6]$ :

$$
v_{g}=\frac{g \cdot d^{2}}{18 \cdot \eta_{f}}\left(\rho_{f}-\rho_{l}\right)
$$

where $d$-diameter of the solid particle;

$\rho_{s}$ - particle material density;

$\rho l$ - liquid density;

$\eta_{f}$ - fluid viscosity.

From the above, it may be seen that the important variables are the viscosity of the water, the difference in specific gravity of the water and hydrocarbons, and the hydrocarbon droplet size. After these are known, the droplet rise velocity, and therefore, the size of the separator that is required, may be calculated. Stokes's Law is only valid for spherical particles or droplets and only in a laminar flow range. Laminar flow may be defined using several different Reynolds numbers, but the Reynolds Number of 500 or less is generally considered laminar flow $[1 ; 6]$.

In the case of air flotation separators, the rising speed of the fat particles fixed on the air bubbles is calculated by the following relation $[1 ; 6]$ :

$$
v_{0}=\frac{g \cdot d_{b}^{2}}{18 \cdot \eta_{f}}\left(\rho_{f}-\rho_{0}\right),
$$

where $d_{b}$-diameter of the air bubble;

$\rho_{f}$ - density of fat particles (oil);

$\rho_{o}-$ air bubble density.

Petroleum products at concentrations of 0,1 to $10 \mathrm{mg} \cdot \mathrm{l}^{-1}$ present in the surface area and wastewater are determined spectrophotometrically according to [11]. Principle of the method: petroleum products together with some substances present in the water are extracted at $\mathrm{pH}<5$ in $\mathrm{CCl}_{4}$ (Carbon tetrachloride). After extraction, petroleum products are dosed through infrared (IR) spectrometry, measuring the absorbance at $2930 \mathrm{~cm}^{-1}$ corresponding to the bond $=\mathrm{CH} 2$. 
The proposed separation system sized for each of the three destination (car wash, fuel station and parking lot) is presented is Fig. 6 .

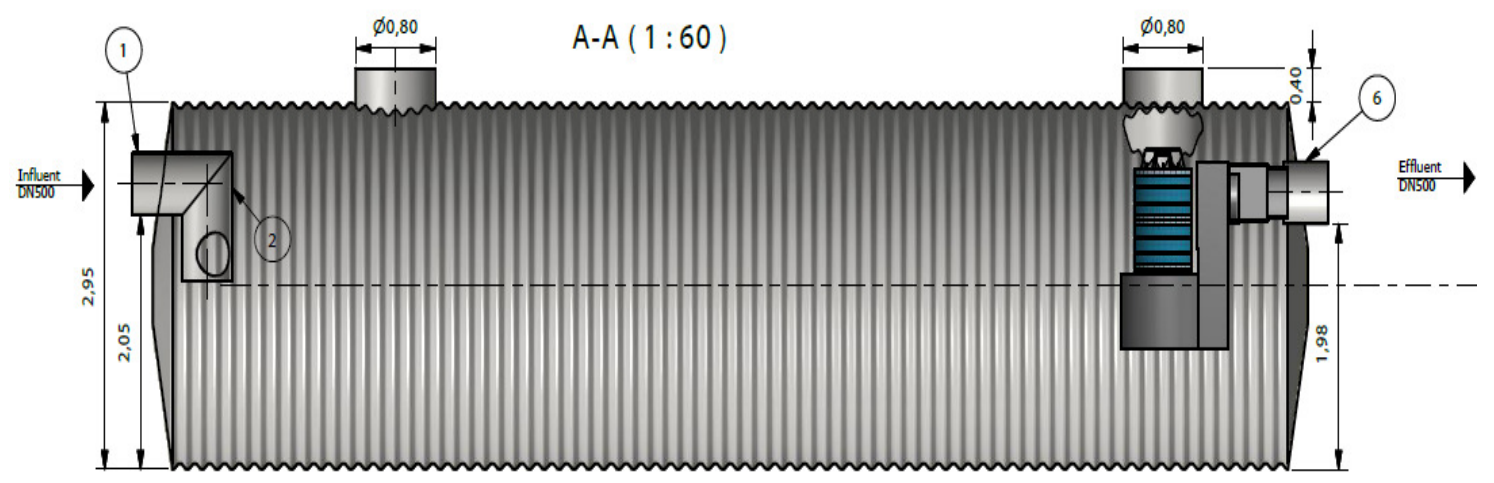

Fig. 6. ENVIA TNS oil and light liquid separator in corrugated steel tank [8]-

informational drawing: 1 - inlet pipe; 2 - diffuser; 3 - coalescence pre filter (only in $2 \mathrm{mg}$ separator); 4 - coalescence main filter; 5 - automatic closing device; 6 - effluent pipe

\section{Results and discussion}

Experiments were carried out with Pureco Environment, ENVIA TNC 60/300-5-A (Fig. 6), ENVIA TNC 150-5 A and ENVIA TNC 600-5-A type hydrocarbon separators in the period 20172018, in Tunari-Ilfov, respectively Sanpaul - Mureş.

The hydrocarbon separator was tested according to [11] and the hydrocarbon index values were followed at the inlet and outlet of the separator.

A complex system, created in steel tanks, was proposed and assembled according to [8]. The system consists of: hydrocarbon separator with coalescing filter, retention tank and pumping station. Thus, by integrating all components into a single container divided into several independent compartments, savings in space and mounting time are achieved. The materials used are almost totally recyclable compared to a conventional concrete retention tank that can no longer be used after its end of life.

Water first enters the hydrocarbon separator where the sludge sedimentation process occurs as well as the process of flotation and coalescence of hydrocarbons and other light liquids. This compartment is separated from the rest of the installation by a sealed wall. The treated water then passes through a discharge nipple into the retention zone. From here it can be used for various activities: watering green spaces, water for sanitary groups, etc., and the surplus can be evacuated to pluvial sewerage or to a natural stream. In this way, the quantities of drinking water used are optimized and pluvial water is efficiently used.

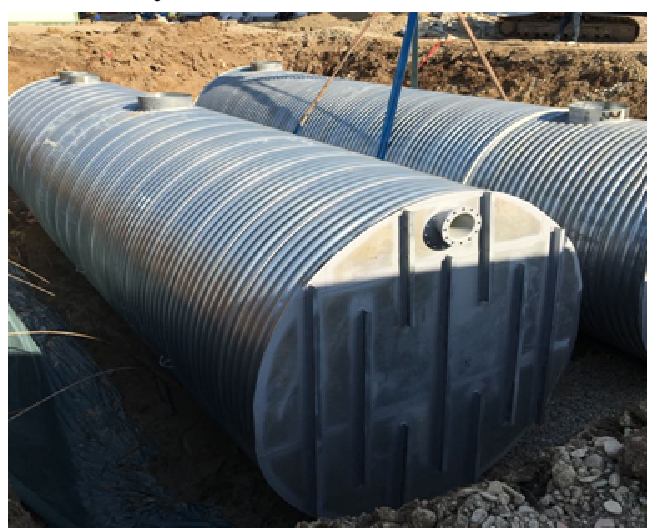

Fig. 7. Hydrocarbon separator with retention tank assembled at beneficiary

It is observed that the inlet concentrations of the parking lot have less hydrocarbon concentration and the fuel station has the highest value After the inlet and outlet concentration is measured it is 
observed that the hydrocarbon separation occurs according to [3], meaning that the hydrocarbons are removed from water the outlet concentration being less than $5 \mathrm{mg} \cdot \mathrm{l}^{-1}$, as it is shown in Fig. 8.

Table 1

Index of hydrocarbons obtained from 3 types of separators

\begin{tabular}{|c|c|c|c|c|c|c|c|c|}
\hline \multirow{2}{*}{$\begin{array}{c}\text { Indicators } \\
\text { analyzed }\end{array}$} & \multicolumn{8}{|c|}{ Hydrocarbon separator ENVIATNP 60/300-5-A (carwash) } \\
\hline & \multicolumn{4}{|c|}{ Values at the separator inlet } & \multicolumn{4}{|c|}{ Values at the separator outlet } \\
\hline \multirow{2}{*}{$\begin{array}{c}\text { Index of } \\
\text { hydrocarbons, } \\
\mathrm{mg}^{-\mathrm{l}^{-1}}\end{array}$} & $\begin{array}{c}\text { Sample } \\
1 \\
\end{array}$ & $\begin{array}{c}\text { Sample } \\
2\end{array}$ & $\begin{array}{c}\text { Sample } \\
3 \\
\end{array}$ & Average & $\begin{array}{c}\text { Sample } \\
1 \\
\end{array}$ & \begin{tabular}{|c|} 
Sample \\
2 \\
\end{tabular} & $\begin{array}{c}\text { Sample } \\
3 \\
\end{array}$ & Average \\
\hline & 10.8 & 11 & 10.5 & & 0.4 & & & \\
\hline \multirow{2}{*}{$\begin{array}{c}\text { Indicators } \\
\text { analyzed }\end{array}$} & \multicolumn{8}{|c|}{ Hydrocarbon separator ENVIATNP 150-5-A (parking lot) } \\
\hline & \multicolumn{4}{|c|}{ Values at the separator inlet } & \multicolumn{4}{|c|}{ Values at the separator outlet } \\
\hline \multirow{2}{*}{$\begin{array}{c}\text { Index of } \\
\text { hydrocarbons, } \\
{\text { mg }\left.\cdot\right|^{-1}}^{-1} \\
\end{array}$} & 1 & 2 & 3 & Average & 1 & 2 & 3 & \\
\hline & 7.9 & 6.5 & 8.1 & & $<0.1$ & $<0.1$ & & \\
\hline \multirow{2}{*}{$\begin{array}{c}\text { Indicators } \\
\text { analyzed }\end{array}$} & \multicolumn{8}{|c|}{ Hydrocarbon separatorENVIATNP 600-5-A (fuel station) } \\
\hline & \multicolumn{4}{|c|}{ he separator inlet } & \multicolumn{4}{|c|}{ Values at the separator outlet } \\
\hline Index of & $\begin{array}{c}\text { Sample } \\
1\end{array}$ & $\begin{array}{c}\text { Sample } \\
2\end{array}$ & $\begin{array}{c}\text { Sample } \\
3\end{array}$ & Average & $\begin{array}{c}\text { Sample } \\
1\end{array}$ & \begin{tabular}{|c|} 
Sample \\
2
\end{tabular} & $\begin{array}{c}\text { Sample } \\
3\end{array}$ & Average \\
\hline & 11.2 & 11 & 10.7 & 10.96 & 0.31 & 0.26 & 0.21 & 0.26 \\
\hline
\end{tabular}

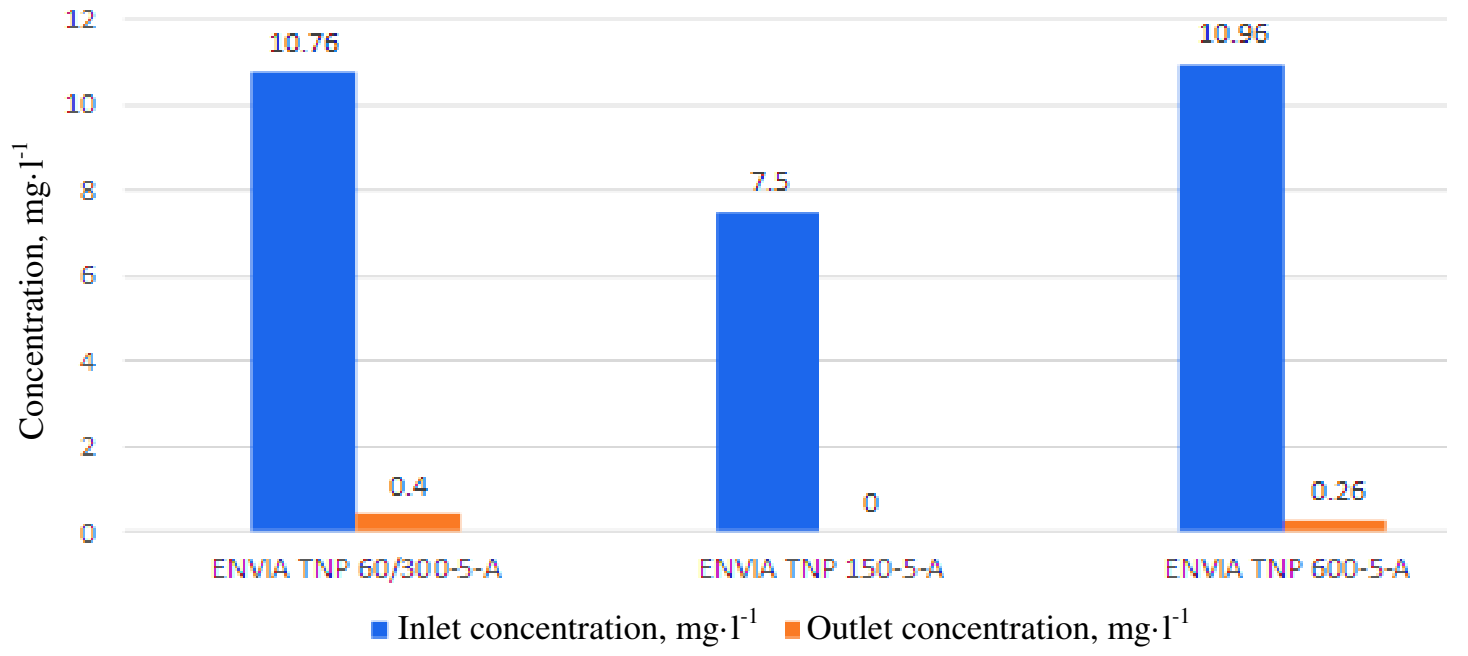

Fig. 8. Inlet and outlet concentration for tested separators

\section{Conclusions}

1. Wastewater treated with a coalescing filter is characterized by concentrations of particulate matter of less than $50 \mathrm{mg} \cdot \mathrm{l}^{-1}$ and the oil and derivatives content of less than $5 \mathrm{mg} \cdot \mathrm{l}^{-1}$, which can be drained to an urban wastewater collection system or to a stream (environment).

2. All three tested separators fell into Class 1 efficiency:

- Class 1: The processed water contains hydrocarbons below $5 \mathrm{mg} \cdot \mathrm{l}^{-1}$, in accordance with the SR EN 858-1 and NTPA-001 analysis report (Coalescing filter model).

- Class 2: The processed water contains hydrocarbons below $100 \mathrm{mg} \cdot 1^{-1}$, in accordance with the SR EN 858-1 and NTPA-002 analysis report (No coalescing filter model).

3. For the chosen optimal hydrocarbon separator these criteria should be considered: effectiveness of treatment, simplicity and reliability of operation, minimum consumable use, minimum production of sludge and used filter/absorbent cartridges, minimum energy use or governmental/regulatory requirements. 
The best and most cost-effective method is usually the simplest and particularly the one that generates the least amount of waste in the pre-treatment facility, while still providing adequate pretreatment.

\section{Acknowledgements}

This work was supported by a GRAND of the Romanian Research and Innovation Ministry, through Programme 1 - Development of the national research-development system, subprogramme 1.2 - Institutional performance - Projects for financing excellence in RDI, contract No. 16PFE.

\section{References}

[1] Kirby S. Mohr. Effective pretreatment for hydrocarbon/VOC removal. WEF Industrial Wastes Technical Conference in Nashville, Tennessee, 1998.

[2] Government Decision 352/2005 Regarding Wastewater Evacuation - NTPA 002/2005 - on Conditions for Wastewater Discharge into the Sewage Systems of Localities and Direct in the Treatment Plants.

[3] Government Decision 352/2005 Regarding Wastewater Evacuation - NTPA 001/2005 - for Establishing Pollutant Load Limits of Industrial and Municipal Wastewater to Discharge into the Natural Receivers.

[4] Standard EN 858-1:2002 - "Principles of product design, performance and testing, marking and quality control".

[5] Standard EN 858-2:2002 - "Separator systems for light liquids (e.g. oil and petrol)" - Part 2: Selection of nominal size, installation, operation and maintenance".

[6] Gary F. Bennett and Nazih K. Shammas, Cap. 3. Separation of Oil from Wastewater by Air Flotation, pp 85-113, Flotation Technology VOLUME 12 Handbook of Environmental Engineering, Humana Press, 2010.

[7] https://www.techneau.com/images/catalogues_UK/catalogues_traitements_des_eaux_UK/ Catalogue_oil_separator.pdf.

[8] http://www.pureco.ro/Separatoare.

[9] Directive 2000/60/EC of the European Parliament and of the Council of 23 October 2000 establishing a framework for Community action in the field of water policy, Available at https://eur-lex.europa.eu/resource.html?uri=cellar:5c835afb-2ec6-4577-bdf8756d3d694eeb.0004.02/DOC_1\&format=PDF;

[10] Installation guide for separation of hydrocarbons with discharge into sewerage networks Available http://www.mdrap.ro/userfiles/reglementari/Domeniul_XIII/13_06_GP_074_2002.pdf.

[11] Standard SR 7877-2/1995 - "Water quality. Determination of petroleum products content. Spectrophotometric method". 